\section{Base Rate (Population)}

Molly E. Zimmerman

Department of Psychology, Fordham University, Bronx, NY, USA

\section{Definition}

The population prevalence of a variable of interest is known as the base rate.

\section{Current Knowledge}

Base rates can be calculated using the following formula (Gouvier 1999):

$$
\begin{aligned}
& \text { Base rate } \\
& =\# \text { cases with condition of interest/ } \\
& \quad \# \text { cases in a population }
\end{aligned}
$$

In neuropsychological settings, base rates are often used to characterize diagnostic accuracy and interpret the sensitivity and specificity of a clinical assessment. The sensitivity of a test is the probability of correctly identifying an individual with impaired functioning as actually being impaired, while the specificity of a test is the probability of correctly identifying an individual with normal functioning as actually being normal (Lezak et al. 2012). When the base rates of a condition are low, the sensitivity of a test may be misleading. When the base rates of a condition are high, the specificity of a test may be misleading (Podell et al. 2003). The neuropsychologist should consider base rates of a disorder when selecting tests for use in a specific population. Knowledge of base rates may also indicate that impairment cutoff scores should be adjusted to interpret diagnostic accuracy. Assessments of malingering or suboptimal effort should also be conducted with consideration of base rates for a particular condition of interest (Gouvier 1999).

\section{Cross-References}

Sensitivity

\section{References and Readings}

Gouvier, W. D. (1999). Base rates and clinical decision making in neuropsychology. In J. J. Sweet (Ed.), Forensic neuropsychology (pp. 27-38). New York: Taylor \& Francis.

Lezak, M. D., Howieson, D. B., Bigler, E. D., \& Tranel, D. (2012). Neuropsychological assessment. Oxford: Oxford University Press.

Podell, K., Defina, P. A., Barrett, P., McCullen, A., \& Goldberg, E. (2003). Assessment of neuropsychological functioning. In I. B. Weiner, D. K. Freedheim, J. A. Schinka, \& W. F. Velicer (Eds.), Handbook of psychology (pp. 443-466). New York: Wiley. 